\title{
Coronary stenosis vasomotion during dynamic exercise before and after PTCA*
}

\author{
T. M. Suter, O. M. Hess, A. Bortone, H. Nonogi, J. Grimm and H. P. Krayenbuehl \\ Department of Internal Medicine, Medical Policlinic, Cardiology, University Hospital, Zürich, \\ Switzerland
}

KEY WORDS: Coronary artery disease, coronary vasomotion, percutaneous transluminal coronary angioplasty, supine bicycle exercise.

Coronary vasomotion was evaluated in eight patients (age $50 \pm 8$ years) with coronary disease before and $3.3 \pm 1.9$ months after successful percutaneous transluminal coronary angioplasty (PTCA). Luminal area of a normal and a stenotic coronary artery was determined before and after PTCA using biplane quantitative coronary arteriography. Patients were studied at rest, during supine bicycle exercise and 5 min after $1.6 \mathrm{mg}$ sublingual nitroglycerin. Workloads before and after PTCA were identical.

Percentage diameter stenosis decreased from $78 \%$ to $24 \%(\mathrm{P}<0.001)$ after PTCA. Mean pulmonary artery pressure increased during exercise from 21 to $40 \mathrm{mmHg}(\mathrm{P}<0.001)$ before and from 19 to $34 \mathrm{mmHg}$ $(\mathrm{P}<0.001)$ after PTCA. Peak exercise pulmonary artery mean pressure was significantly $(\mathrm{P}<0.05)$ lower after PTCA. Normal coronary arteries showed a minimal increase in mean luminal area before $(+2 \% ; N S)$ as well as after $(+6 \% ;$ NS) PTCA. Nitroglycerin produced dilation of the normal vessel segment to a similar extent pre- $(+27 \% ; \mathrm{P}<0.001)$ and post- $(+31 \% ; \mathrm{P}<0.001)$ PTCA. In contrast, stenotic vessel segments showed coronary vasoconstriction during exercise before PTCA $(-28 \% ; \mathrm{P}<0.01) ;$ after PTCA, exercise-induced vasoconstriction of the diseased segment was minimal $(-4 \% ; N S)$. Nitroglycerin was associated with vasodilation of the stenotic vessel segment before (+17\%; NS) as well as after $(+26 \% ; \mathrm{P}<0.005)$ PTCA.

Thus, exercise-induced coronary vasoconstriction of stenotic coronary arteries is observed before as well as after PTCA, but vasoconstriction after PTCA is significantly less than before PTCA. Coronary vasomotion appears to be modified in a positive way by PTCA, but the exact mechanism remains unclear.

\section{Introduction}

Coronary vasomotion plays an important role in the regulation of coronary flow at rest and during physical exercise ${ }^{[1-3]}$. Not only normal but also stenotic coronary arteries show vasomotion during exercise since approximately $70 \%$ of all coronary stenoses have a normal musculo-elastic wall segment at the site of the stenosis ${ }^{[4]}$. Previous studies have indicated that normal coronary arteries dilate but diseased coronary arteries constrict during dynamic exercise $^{[3]}$. Thus, the purpose of the present study was to evaluate the effect of percutaneus transluminal coronary angioplasty (PTCA) on coronary vasomotion at rest and during exercise in patients with coronary artery disease before and after PTCA.

Address for correspondence: Otto M. Hess, M.D., Medical Policlinic, Cardiology, University Hospital Raemistrasse 100, CH-8091 Zürich, Switzerland.

* This work was supported by a grant of the Swiss National Science Foundation.

\section{Methods and patients}

\section{STUDY POPULATION}

Eight male patients (mean age 50 years, range 39-61 years) were included in the present study (Table 1). All patients had a history of exerciseinduced angina pectoris and four had previous myocardial infarction. Upright bicycle exercise testing was performed in all patients before and after PTCA. ST-segment depression of more than $0.1 \mathrm{mV}$ was found in six patients (mean $0.24 \pm 0.14 \mathrm{mV}$ ) before PTCA. No ST-segment depression was present after PTCA except in one patient $(0.28 \mathrm{mV}$ in patient 4). Angina pectoris occurred in five patients before and in the patient with ST-segment depression after PTCA. Patients were selected for the present study on a consecutive basis when the following inclusion criteria were fulfilled: (1) coronary artery stenosis clearly visible on angiography for quantitative evaluation; (2) successful PTCA; and 
Table 1 Patient characteristics

\begin{tabular}{|c|c|c|c|c|c|c|c|}
\hline \multirow[b]{2}{*}{ Patient } & \multirow{2}{*}{$\begin{array}{c}\text { age } \\
\text { (years) }\end{array}$} & \multicolumn{2}{|c|}{ NYHA class } & \multicolumn{2}{|c|}{ PWC } & \multicolumn{2}{|c|}{$\%$ stenosis } \\
\hline & & pre & post & pre & post & pre & post \\
\hline 1 & 52 & II & I & 100 & 100 & 76 & 24 \\
\hline 2 & 39 & II & I & 101 & 101 & 63 & 27 \\
\hline 3 & 46 & II & II & 99 & 99 & 80 & 23 \\
\hline 4 & 44 & III & II & 50 & 75 & 79 & 11 \\
\hline 5 & 46 & II & I & 102 & 115 & 85 & 31 \\
\hline 6 & 56 & II & I & 107 & 107 & 79 & 6 \\
\hline 7 & 61 & II & I & 101 & 101 & 78 & 48 \\
\hline 8 & 54 & III & II & 76 & 76 & 85 & 24 \\
\hline Mean & 50 & $2 \cdot 3$ & $1 \cdot 4^{* * *}$ & 92 & 97 & 78 & $24^{* * *}$ \\
\hline $\mathrm{SD}$ & 7 & 0.5 & 0.5 & 19 & 14 & 7 & 20 \\
\hline
\end{tabular}

NYHA: functional class according to the New York Heart Association scheme; PWC: physical working capacity in percentage of the age-, sex- and height-corrected normal value; $\%$ stenosis: percentage diameter stenosis; pre, post: before, after PTCA; ${ }^{* * *} p<0.001$ (pre vs post); SD: standard deviation.

(3) coronary arteriography after PTCA (mean $3 \cdot 3$ months, range 2-6 months).

\section{CARDIAC CATHETERIZATION}

Patients underwent right and left heart catheterization for diagnostic purposes. Informed consent was obtained from all patients. Premedication consisted of $10 \mathrm{mg}$ chlordiazepoxide administered orally $1 \mathrm{~h}$ before the procedure. Aortic pressure was measured with a 8 F Judkins-catheter introduced from the right femoral artery. Pulmonary artery pressure was measured with a $6 \mathrm{~F}$ pacing catheter with a side lumen for pressure recordings introduced from the right femoral vein. PTCA was performed 1-4 weeks after diagnostic coronary arteriography.

STUDY PROTOCOL

After routine coronary arteriography (Judkins technique) an interval of at least $10 \mathrm{~min}$ was allowed for dissipation of the effect of the contrast medium (Iopamiro $370 \mathrm{R}=$ iopamidol $755 \cdot 2 \mathrm{mg}$ $\mathrm{ml}^{-1}$, trometamol $1 \mathrm{mg} \mathrm{ml}^{-1}$ ) on coronary vasomotion. Subsequently, the patient's feet were attached to the ergometer (Siemens-Elema AG, model $380 \mathrm{~B})$. Aortic and pulmonary artery pressures were recorded immediately before each coronary angiogram (Table 2). Biplane coronary angiography in orthogonal projection was carried out at rest and repeated at the end of each level of exercise which was begun at 50-75 W and was increased every $2 \mathrm{~min}$ in increments of $25-50 \mathrm{~W}$. The exercise test was terminated because of anginal pain, fatigue or STsegment depression of more than $0.2 \mathrm{mV}$. The average workload was $115 \mathrm{~W}$. The same exercise protocol was used for each patient at recatheterization after PTCA. At the end of the exercise test, $1.6 \mathrm{mg}$ nitroglycerin was administered sublingually and biplane coronary arteriography was repeated 3 and $5 \mathrm{~min}$ thereafter. There were no complications

Table 2 Haemodynamic data

\begin{tabular}{|c|c|c|c|c|c|c|c|c|c|}
\hline & \multicolumn{3}{|c|}{$\begin{array}{c}\text { HR } \\
\left(\text { beats } \min ^{-1} \text { ) }\right.\end{array}$} & \multicolumn{3}{|c|}{$\underset{(\mathrm{mmHg})}{\mathrm{MAP}}$} & \multicolumn{3}{|c|}{$\begin{array}{c}\text { MPAP } \\
(\mathrm{mmHg})\end{array}$} \\
\hline & $\mathbf{R}$ & $\mathrm{EX}$ & NTG & $\mathbf{R}$ & EX & NTG & $\mathbf{R}$ & EX & NTG \\
\hline $\begin{array}{l}\text { Pre mean } \\
\text { SD }\end{array}$ & $\begin{array}{r}67 \\
7\end{array}$ & $\begin{array}{c}113^{* * *} \\
15\end{array}$ & $\begin{array}{c}79^{*} \\
8\end{array}$ & $\begin{array}{r}104 \\
15\end{array}$ & $\begin{array}{r}109 \\
23\end{array}$ & $\begin{array}{l}93 \\
22\end{array}$ & $\begin{array}{r}21 \\
6\end{array}$ & $\begin{array}{c}40^{* * *} \\
7\end{array}$ & $\begin{array}{r}19 \\
5\end{array}$ \\
\hline $\begin{array}{l}\text { Post mean } \\
\text { SD }\end{array}$ & $\begin{array}{l}78 \\
13\end{array}$ & $\begin{array}{c}115^{* * *} \\
15\end{array}$ & $\begin{array}{l}85 \\
15\end{array}$ & $\begin{array}{r}103 \\
15\end{array}$ & $\begin{array}{c}112^{* *} \\
10\end{array}$ & $\begin{array}{l}93 \\
13\end{array}$ & $\begin{array}{r}19 \\
5\end{array}$ & $\begin{array}{c}134^{* * *} \\
8\end{array}$ & $\begin{array}{r}15 \\
5\end{array}$ \\
\hline
\end{tabular}

HR: heart rate; MAP: mean aoric pressure; MPAP: mean pulmonary artery pressure; $R$ : rest; Ex: peak exercise; NTG: sublingual nitroglycerin; pre, post: before, after $P$ TCA; ${ }^{*} P<0 \cdot 05,{ }^{* *} P<0 \cdot 01$, ${ }_{* * * P}<0.001$ (vs rest); SD: standard deviation. 
related to the procedure in the eight patients before and after PTCA.

\section{QUANTITATIVE CORONARY ARTERIOGRAPHY}

The currently used technique for quantitative coronary arteriography has been described previously ${ }^{[3,5]}$. Quantitative evaluation of biplane coronary arteriography was carried out in a blinded fashion. Tracings were made manually from both projections during diastasis or end-diastole. Each vessel segment was analysed from six different frames and the results were averaged to reduce sampling error. A section of the catheter of known dimensions was traced as a scaling factor. The tracings of the coronary vessel segment were digitized manually and analysed on a PDP 11/34 computer ${ }^{[3,5]}$. The luminal area of a normal and a stenotic vessel segment was calculated in each patient and expressed in absolute values and in percent of the resting value (see Table 3, Figs. 1 and 2). Quantitative evaluation of the normal and stenotic vessel segment was repeated after PTCA using certain landmarks (e.g. side-branches) for exact identification of the evaluated segments prior to PTCA. In one patient difficulties were encountered in visualization of the stenosis in the left anterior oblique projection before PTCA due to low contrast; in this patient a single (RAO) view was used before and after PTCA.

\section{STATISTICAL ANALYSIS}

Statistical comparisons of haemodynamic and angiographic data at rest and during exercise as well as after nitroglycerin were carried out by a two-way analyis of variance for repeated measures. Compari-

Table 3 Calculated luminal areas

\begin{tabular}{|c|c|c|c|c|c|c|}
\hline \multirow[b]{3}{*}{ Patient } & \multicolumn{6}{|c|}{ Normal coronary luminal area $\left(\mathrm{mm}^{2}\right)$} \\
\hline & \multicolumn{2}{|c|}{$\mathbf{R}$} & \multicolumn{2}{|c|}{ EX } & \multicolumn{2}{|c|}{ NTG } \\
\hline & pre & post & pre & post & pre & post \\
\hline 1 & $5 \cdot 4$ & $5 \cdot 0$ & $5 \cdot 5$ & $5 \cdot 7$ & $6 \cdot 8$ & $6 \cdot 4$ \\
\hline 2 & $8 \cdot 0$ & 6.9 & 9.0 & $7 \cdot 5$ & $10 \cdot 4$ & $8 \cdot 4$ \\
\hline 3 & $8 \cdot 0$ & 6.9 & $9 \cdot 1$ & $6 \cdot 8$ & $10 \cdot 6$ & 7.9 \\
\hline 4 & $3 \cdot 2$ & $3 \cdot 5$ & 3.4 & $4 \cdot 0$ & $4 \cdot 0$ & $5 \cdot 3$ \\
\hline 5 & 9.9 & 8.6 & 9.7 & $8 \cdot 3$ & $10 \cdot 2$ & 9.8 \\
\hline 6 & 2.9 & $3 \cdot 2$ & 2.6 & $3 \cdot 1$ & $4 \cdot 2$ & $4 \cdot 5$ \\
\hline 7 & $4 \cdot 3$ & $4 \cdot 2$ & $3 \cdot 8$ & $4 \cdot 5$ & $5 \cdot 4$ & $5 \cdot 5$ \\
\hline 8 & $1 \cdot 3$ & $1 \cdot 6$ & $1 \cdot 4$ & $1 \cdot 6$ & $1 \cdot 7$ & $2 \cdot 4$ \\
\hline \multirow{4}{*}{$\begin{array}{l}\text { Mean } \\
\text { SD }\end{array}$} & $5 \cdot 4$ & $5 \cdot 0$ & $5 \cdot 6$ & $5 \cdot 2$ & $6 \cdot 7^{* * *}$ & $6 \cdot 3^{*}$ \\
\hline & 2.9 & $2 \cdot 3$ & $3 \cdot 3$ & $2 \cdot 3$ & $3 \cdot 4$ & $2 \cdot 4$ \\
\hline & \multicolumn{6}{|c|}{ Stenotic coronary luminal area $\left(\mathrm{mm}^{2}\right)$} \\
\hline & \multicolumn{2}{|c|}{$\mathrm{R}$} & \multicolumn{2}{|c|}{ EX } & \multicolumn{2}{|c|}{ NTG } \\
\hline Patient & pre & post & pre & post & pre & post \\
\hline 1 & 0.6 & 3.7 & 0.6 & $3 \cdot 7$ & 0.7 & $5 \cdot 0$ \\
\hline 2 & $1 \cdot 0$ & $3 \cdot 3$ & 0.7 & $3 \cdot 7$ & 1.0 & $3 \cdot 8$ \\
\hline 3 & 0.5 & $3 \cdot 1$ & 0.4 & $2 \cdot 7$ & 0.7 & $3 \cdot 1$ \\
\hline 4 & 0.95 & 3.75 & 0.7 & 3.9 & 0.98 & $5 \cdot 2$ \\
\hline 5 & 0.3 & 1.6 & 0.2 & $1 \cdot 3$ & 0.4 & 1.9 \\
\hline 6 & 0.9 & 6.0 & 0.4 & $4 \cdot 4$ & 0.7 & 7.4 \\
\hline 7 & 0.7 & $1 \cdot 5$ & 0.4 & $1 \cdot 5$ & 1.0 & $2 \cdot 2$ \\
\hline 8 & 0.65 & 2.63 & 0.55 & $2 \cdot 95$ & 0.78 & $3 \cdot 8$ \\
\hline Mean & 0.7 & $3 \cdot 2^{+}$ & $0.49^{* *}$ & $3 \cdot 02^{+}$ & 0.78 & $4 \cdot 0^{* *+}$ \\
\hline SD & 0.24 & $1 \cdot 4$ & $0 \cdot 17$ & $1 \cdot 13$ & 0.21 & $1 \cdot 8$ \\
\hline
\end{tabular}

R: rest; peak exercie; NTG: sublingual nitroglycerin; pre, post: before, after PTCA; $* P<0.01$ (vs R); ${ }^{*} P<0.01$ (vs R); ${ }^{* * *} P<0.001$ (vs R); ${ }^{+} P<0.001$ (vs pre) SD: standard deviation. 


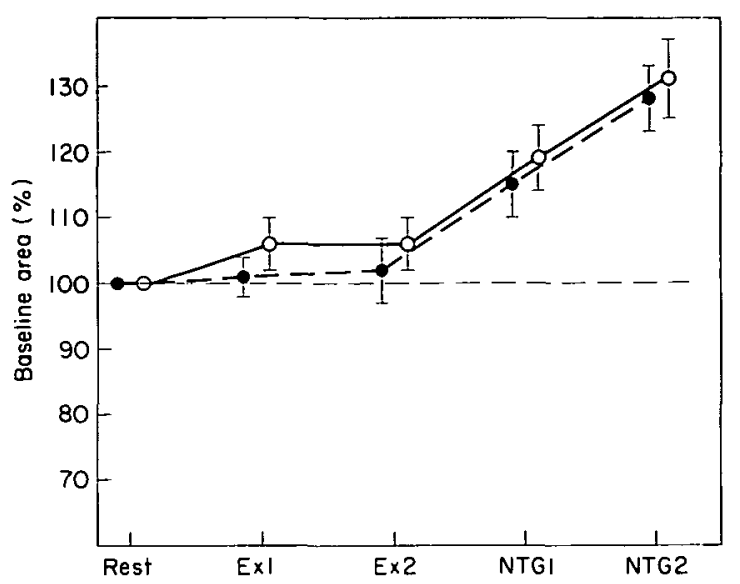

Figure 1 Coronary vasomotion of the normal vessel segment before (closed symbols) and after (open symbols) PTCA. Ex 1: first level of exercise; Ex 2: second level of exercise; NTG1: $3 \mathrm{~min}$ after $1.6 \mathrm{mg}$ sublingual nitroglycerin; NTG2: $5 \mathrm{~min}$ after $1.6 \mathrm{mg}$ sublingual nitroglycerin.

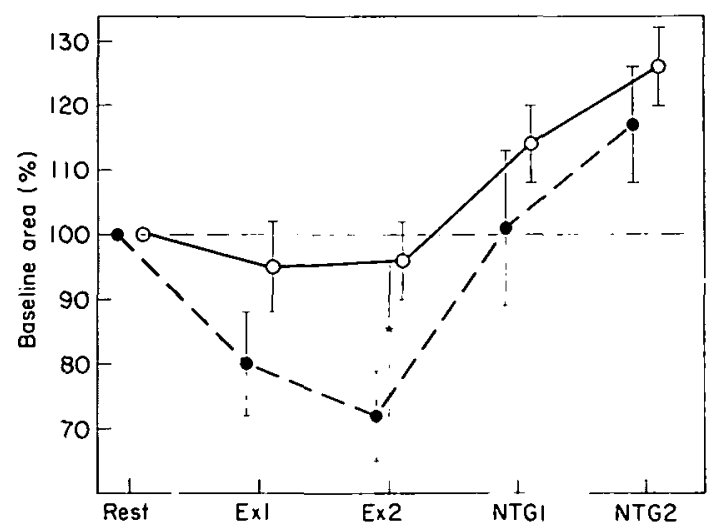

Figure 2 Coronary vasomotion of the stenotic vessel segment before (closed symbols) and after (open symbols) PTCA. Abbreviations are as in Fig. 1. ${ }^{*} P<0.01$.

sons before and after PTCA were made by an paired Student's $t$ test. In all figures, mean values \pm 1 standard error are reported.

\section{Results}

\section{PATIENT CHARACTERISTICS (TABle 1)}

Functional class (according to the New York Heart Association system) decreased significantly after successful PTCA. Physical working capacity during upright bicycle exercise increased slightly, although not significantly, from 92 to $97 \%$ after PTCA. Per- centage diameter stenosis was $78 \%$ before and $24 \%$ after angioplasty.

\section{HAEMODYNAMIC DATA (TABLE 2)}

Heart rate and mean pulmonary artery pressure increased significantly during exercise before as well as after PTCA. Mean pulmonary artery pressure during peak exercise was, however, significantly lower post than prePTCA $(P<0.05)$. There was a slight but statistically not significant increase in mean aortic pressure before, but a significant increase after PTCA $(P<0.01)$.

ANGIOGRAPHIC DATA (TABLES 3, FIGS 1 AND 2)

Normal coronary arteries (Fig. 1) showed a minimal increase in mean luminal area during supine bicycle exercise before $(+2 \%$; NS) as well as after ( $+6 \%$; NS) PTCA. Sublingual administration of nitroglycerin was associated with a definite increase in normal vessel area before $(+27 \% ; P<0.001)$ and after $(+31 \% ; P<0.001)$ PTCA.

Stenotic coronary arteries (Fig. 2) showed before PTCA a significant reduction in vessel area during supine bicycle exercise $(-28 \% ; P<0.01)$ and an increase after sublingual administration of nitroglycerin (+17\%; NS). Bicycle exercise after PTCA was associated with a slight decrease in minimal luminal area of the treated (formerly stenotic) vessel segment $(-4 \%$; NS) followed by a significant increase after sublingual administration of nitroglycerin $(+26 \% ; P<0.01)$. The decrease in minimal luminal area of the stenotic vessel segment (Fig. 2) was significantly less $(P<0.01)$ after than before PTCA.

\section{Discussion}

Coronary blood flow is determined by several factors such as perfusion pressure, coronary vascular resistance, metabolic demands and vasomotor tone ${ }^{[6]}$. In normal coronary arteries, blood flow increases three to five times during physical exercise, whereas in stenotic coronary arteries the increase in blood flow is strongly dependent on the severity of the stenosis. The actual regional blood flow is, however, not solely determined by the luminal area but is the result of the complex interplay of the aforementioned haemodynamic, metabolic and neural factors. Several studies ${ }^{[6,7]}$ have established the presence of both alpha- and beta-adrenergic receptors in animal and human coronary arteries. An 
increase in alpha-adrenergic tone has been associated with coronary artery vasoconstriction, whereas an increase in beta-receptor tone is accompanied by coronary artery vasodilation ${ }^{[5]}$. The exact mechanism responsible for the decrease in minimal luminal area of the stenotic vessel segment during exercise is not clear, and might involve active vasoconstriction or a passive collapse of the disease-free vessel segment within the stenosis, due to increased coronary blood flow ${ }^{[3]}$. Active vasoconstriction seems, however, more likely to be responsible for exercise-induced stenosis narrowing than a passive collapse. The following two mechanisms could explain this phenomenon: endothelial dysfunction with insufficient production of the endotheliumderived relaxing factor (= EDRF) or platelet aggregation with release of thromboxane $\mathrm{A}_{2}$ and serotonin ${ }^{[3,9]}$. Which of these two mechanisms is responsible for exercise-induced stenosis narrowing is not clear and cannot be determined from present data. It is, however, obvious that this phenomenon can aggravate myocardial ischaemia during physical exercise and represents, therefore, an important mechanism in the pathophysiology of angina pectoris.

The purpose of the present study was to evaluate coronary vasomotion in patients with stable angina pectoris and to examine the effect of PTCA on exercise-induced stenosis narrowing. The question was if the increase in stenosis area after PTCA could influence coronary vasomotion of the stenotic vessel segment.

\section{CORONARY VASOMOTION BEFORE AND AFTER PTCA}

Normal coronary arteries showed minimal vasodilation during dynamic exercise with a further increase after sublingual administration of nitroglycerin (Fig. 1). Exactly the same behaviour was found before and after PTCA as one would expect, but the extent of coronary vasodilation was smaller $(+2 \%$ pre-, $+6 \%$ postPTCA) than that of non-stenotic vessels reported previously ${ }^{[3,5,9]}$. It might be that the wall of the so-called 'normal vessel' in this study was not truly normal and elicited a depressed responsiveness to physiologic dilatory stimuli. In patients with diseased but not visibly stenotic coronary arteries, no dilation during exercise has been observed previously ${ }^{[10,11]}$.

Stenotic coronary arteries showed vasoconstriction during exercise with a decrease in minimal luminal area of approximately $30 \%$ (Fig. 2). Similar data have been reported by Gage and coworkers ${ }^{[3]}$. All

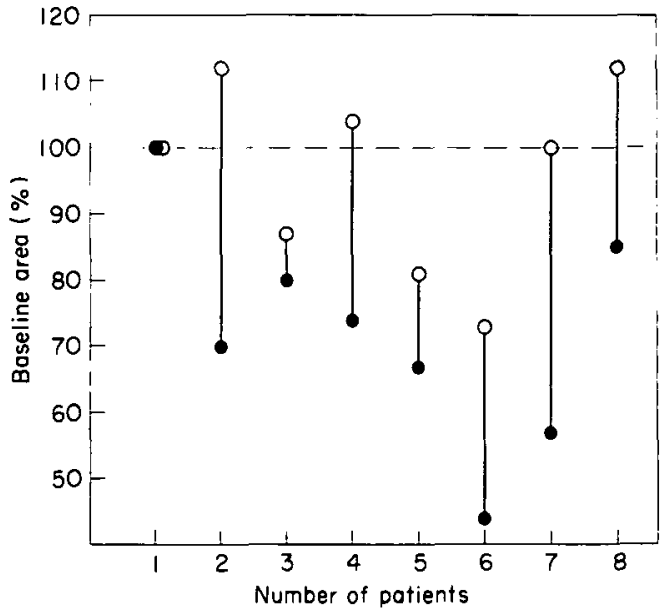

Figure 3 Changes in coronary luminal area of the stenotic vessel segment during peak exercise before (closed symbols) and after (open symbols) PTCA. Individual data (in \% of the baseline area) are given for each patient. Vasoconstriction occurred in all except one patient before, but only in three patients after PTCA.

but one patient showed vasoconstriction during exercise in the present study (Fig. 3). PTCA was associated with an increase in minimal luminal area from 0.7 to $3.2 \mathrm{~mm}^{2}$ and a decrease in percentage diameter stenosis from 78 to $24 \%$. After PTCA coronary vessel segments showed significantly less vasoconstriction during peak exerise than before PTCA (pre$-28 \%$, post- $-4 \% ; P<0.01$; Fig. 3 ). Three of the eight patients elicited vasodilation during postPTCA exercise, whereas two patients showed no vasomotion and three had less but persisting vasoconstriction (Fig. 3). The patient with ST-segment depression $(0.28 \mathrm{mV}$, patient 4$)$ in the upright exercise test after PTCA showed minimal vasodilation (+4\%; Fig. 3) during exercise. Residual stenosis was $11 \%$ in this patient (before PTCA: $79 \%$ ).

The stenotic vessel segments were able to dilate both before and after PTCA, since sublingual administration of nitroglycerin was associated with an increase in minimal luminal area of $17 \%$ before and $26 \%$ after PTCA, respectively. However vasodilation did not occur during exercise; hence some other mechanism must have influenced coronary vasomotion. Coronary vasodilation during exercise might be dependent on an intact endothelium with an adequate production of the endothelium-derived relaxing factor. 'Healing' after PTCA might lead to re-endothelialization and improvement of endothelial function. 


\section{LIMITATIONS OF THE STUDY}

The accuracy of quantitative coronary arteriography has been established previously in our laboratory ${ }^{[3,5]}$ Brown and coworkers ${ }^{[12]}$ reported that the accuracy of quantitative coronary arteriography is within $0.08 \mathrm{~mm}$ for measurement of known dimensions and $0.10 \mathrm{~mm}$ for minimum diameter estimates. The changes observed in our study, such as the $0.21 \mathrm{~mm}^{2}(0.15 \mathrm{~mm}$ diameter $)$ decrease in stenosis area at peak exercise, are small but clearly larger than reported angiographic resolution. Therefore, the observed changes after several interventions can be considered representative, even with monoplane assessment.

\section{References}

[1] Brown BG, Bolson EL, Dodge HT. Dynamic mechanisms in human coronary stenosis. Circulation 1984; 42: 917-22.

[2] Mates RE, Gupta RL, Bell AC, Klocke FJ. Fluid dynamics of coronary artery stenosis. Circ Res 1978; 42: $152-62$.

[3] Gage JE, Hess OM, Murakami T, Ritter M, Grimm J, Krayenbuehl HP. Vasoconstriction of stenotic coronary arteries during exercise in patients with classic angina pectoris: reversibility by nitroglycerin. Circulation 1986; 73: 865-76.

[4] Freudenberg H, Lichtlen PR. The normal wall segment in coronary stenosis-a postmortem study. $\mathrm{Z}$ Kardiol 1981; 70: 863-9.
[S] Gaglione A, Hess OM, Corin WJ, Ritter M, Grimm J, Krayenbuehl HP. Is there coronary vasoconstriction after intracoronary beta-adrenergic blockade in patients with coronary artery disease? J Am Coll Cardiol 1987; 10: 299-310.

[6] Mohrman DE, Feigl EO. Competition between sympathetic vasoconstriction and metabolic vasodilatation in the canine coronary circulation. Circ Res 1978; 42: $79-86$.

[7] Feigl EO. Sympathetic control of coronary circulation. Circ Res 1967; 20: 262-71.

[8] Saner HE, Gobel FL, Salomonowitz E, Erlien DA, Edwards JE. The disease-free wall in coronary artherosclerosis: its relation to degree of obstruction. J Am Coll Cardiol 1985; 6: 1096-9.

[9] Bortone A, Hess OM, Gaglione A, Nonogi H, Grimm $\mathrm{J}$, Krayenbuehl HP. Effect of intracoronary and intravenous propranolol on coronary vasomotionat rest and during exercise. Circulation 1988; 78 (Suppl II); II-455 (abstr).

[10] Hess OM, Bortone A, Eid K et al. Coronary vasomotor tone during static and dynamic exercise. Eur Heart J 1988; 10 (Suppl F).

[11] Gordon JB, Zebede J, Wayne RR, Mudge GH, Ganz $P$, Selwyn AP. Coronary constriction with exercise: possible role for endothelial dysfunction and alpha tone. Circulation 1986; 74 (Suppl II): II-481 (abstr).

[12] Brown BG, Bolson E, Frimer M, Dodge HT. Quantitative coronary arteriography: estimation of dimensions, hemodynamic resistance, and atheroma mass of coronary artery lesions using arteriogram and digital computation. Circulation 1977; 55: 329-37. 